\title{
Corsica: A 20-Yr Multi-Mission Absolute Altimeter Calibration Site
}

\author{
P. Bonnefond ${ }^{a}$, P. Exertier ${ }^{\text {b,c }}$, O. Laurain ${ }^{b}$, T. Guinle $^{d}$, P. Féménias ${ }^{\text {e }}$ \\ ${ }^{a}$ SYRTE, Observatoire de Paris, PSL Research University, CNRS, Sorbonne Universités, UPMC Univ. \\ Paris 06, LNE, 77 avenue Denfert-Rochereau, 75014 Paris, France \\ ${ }^{b}$ Geoazur, Observatoire de la Côte d'Azur, 250 rue Albert Einstein - CS 10269, 06905 Sophia- \\ Antipolis Cedex, France \\ ${ }^{c}$ GET, Observatoire Midi-Pyrénées, 14, avenue Edouard Belin, 31400 Toulouse, France \\ ${ }^{d}$ CNES, 18, avenue Edouard Belin, 31401 Toulouse Cedex 9, France \\ ${ }^{e}$ ESA/ESRIN, Via Galileo Galilei CP64, I-00044 Frascati, Italy
}

\begin{abstract}
Initially developed for monitoring the performance of TOPEX/Poseidon and follow-on Jason legacy satellite altimeters, the Corsica geodetic facilities that are located both at Senetosa Cape and near Ajaccio have been developed to calibrate successive satellite altimeters in an absolute sense. Since 1998, the successful calibration process used to calibrate most of the oceanographic satellite altimeter missions has been regularly updated in terms of in situ instruments, geodetic measurements and methodologies. In this study, we present an assessment of the long-term stability of the in situ instruments in terms of sea level monitoring that include a careful monitoring of the geodetic datum. Based on this 20 -yr series of sea level measurements, we present a review of the derived absolute Sea Surface Height (SSH) biases for the following altimetric missions based on the most recent reprocessing of their data set: TOPEX/Poseidon and Jason-1/2/3, Envisat and ERS-2, CryoSat-2, SARAL/AltiKa and Sentinel-3A\&B. For the longest time series the standard error of the absolute SSH biases is now at a few millimeters level which is fundamental to maintain the high level of confidence that scientists have in the global mean sea level rise.
\end{abstract}

Keywords: satellite altimetry; in situ; tide gauges; GNSS; calibration; validation

\section{INTRODUCTION}

Current estimates of regional and global change in mean sea level are only possible through careful and continuous Calibration and Validation of the altimetry missions. Cross calibration of past, present and future altimetry missions will remain essential for the realization of a continuous and homogeneous series of sea level (Ablain et al., 2015; Fu and Haines, 2013). There is no doubt, however, that calibration of an altimeter requires a multiple approach, including using both in situ calibration sites and global studies based on the global tide gauge network. The relative calibration between different missions flying on the same period through crossover analysis or by along-track comparisons during tandem phase of the missions is also an important contribution for the Calibration/Validation activities. All these techniques are considered complementary and fundamental in oceanography (Ablain et al., 2010; Bonnefond et al., 2010; Haines et al., 2010; Mertikas et al., 2018; Watson et al., 2011).

The traditional concept of in situ calibration of an altimeter involves direct satellite overflight of a site equipped with dedicated instruments. If it is essential that such a calibration site has means of in situ sea-level observation - using for example a classic tide gauge, a mooring or a floating system equipped with GNSS - , it is fundamental, however, to link the observed 
sea level to a terrestrial reference frame comparable to that used to analyze altimetry satellite measurements. In an ideal situation, the site of the experiment is located on a repetitive ground track (or better still on a crossover point between ascending and descending tracks), and far enough off the coast to avoid contamination of the altimeter or radiometer by reflections on land.

The potential for a number of geographically correlated errors within the altimetry system underscores the need for calibration experiment to be placed at different locations across the globe. The ability to sample the various systematic errors and characterize them in an absolute sense is one of the important advantages of a set of well-distributed calibration sites on Earth. This ensures a diverse sampling of ocean and atmospheric conditions, and allows the use of different methodologies and processing software to help isolate systematic errors in all geodetic techniques involved.

The Corsica experiment which makes a collective reference to the instrumentation and facilities located in the western part of the Mediterranean at Ajaccio-Aspretto, Senetosa, and on the island of Capraia (Italy), is used to maximize the capability of performing the absolute calibration of a range of altimeters (see Figure 1 left for the respective sites and the satellites ground tracks). On the other hand, it implies preserving the coherence of the overall Corsica experiment in terms of geodesy despite the diversity of instruments, approaches and geophysical conditions in addition to the range of distances between the sites.

One of the key points in the absolute calibration process is that the relationship between the height of the sea surface from the altimetry data and that from the in situ measurements is mainly affected by a difference of height due to the local shape of the geoid. Because in Corsica the average slope of the geoid is of a few $\mathrm{cm}$ per $\mathrm{km}$, a specific GPS campaign was carried out from the beginning (1999) to determine the marine geoid near the Senetosa Cape on an area of $20 \mathrm{~km}$ long and $5.4 \mathrm{~km}$ wide centered on the ground track $\# 085$ of T/P and Jason (Bonnefond et al., 2003a). In a complementary way, a similar measurement's campaign was carried out in 2005 in the Ajaccio area under the ground track \#130 of ERS, Envisat and later SARAL/AltiKa. We must indicate that, for logistical reasons, the Capraia site is in standby since the realization of the sea surface mapping in 2004 .

Since the development of the Ajaccio and Senetosa sites, absolute calibration were performed independently at each site depending of the overflying mission without any means of verifying the reliability of their respective geodetic datum (absolute sense). However, thanks to the configuration of Sentinel-3A repeat ground track and some CryoSat-2 passes, it has been possible to determine two distinct SSH biases at each site for each altimeter overflying both Senetosa and Ajaccio with a time delay of about five seconds (about $37 \mathrm{~km}$, see Figure 1, middle). As a consequence, it allowed us to compare these biases and thus interconnect both datum (Bonnefond et al. 2018a). Moreover, because the SARAL/AltiKa mission was placed on a drifting orbit phase since July 2016, a similar interconnection between both Ajaccio and Senetosa datum has been achieved (Bonnefond et al. 2018b). The results of these two papers are summarized and updated in the present paper (see sections 4.3, 4.4 and 4.5$)$.

Since 1998, the success of the Corsica calibration site is mainly based on the ability to maintain accuracy and stability of the involved measurement systems on the one hand, and on the other hand to regularly update the calibration process for successive and different oceanographic satellite altimeter missions (repeatitivity, Low Resolution Mode, Synthetic Aperture Radar). Thus over more than 20 years, we developed well-defined protocols to measure any vertical offset or drift for stability and we achieved many geodetic campaigns 
and instrument calibrations for accuracy (see details in Bonnefond et al. 2003b, 2010, 2015, 2018a). This goes in line with the concept of FRM (Fiducial Reference Measurement, https://www.frm4alt.eu) and the associated concept of FRM's compliancy to notably in terms of protocol, regular calibration of the in situ instruments, uncertainty measurement. This paper focuses on the analysis of the geodetic datum stability (section 2), the in situ instruments stability (section 3) and a complete reanalysis of the missions overflying the Corsica calibration facilities using the most recent reprocessing of their data (section 4).

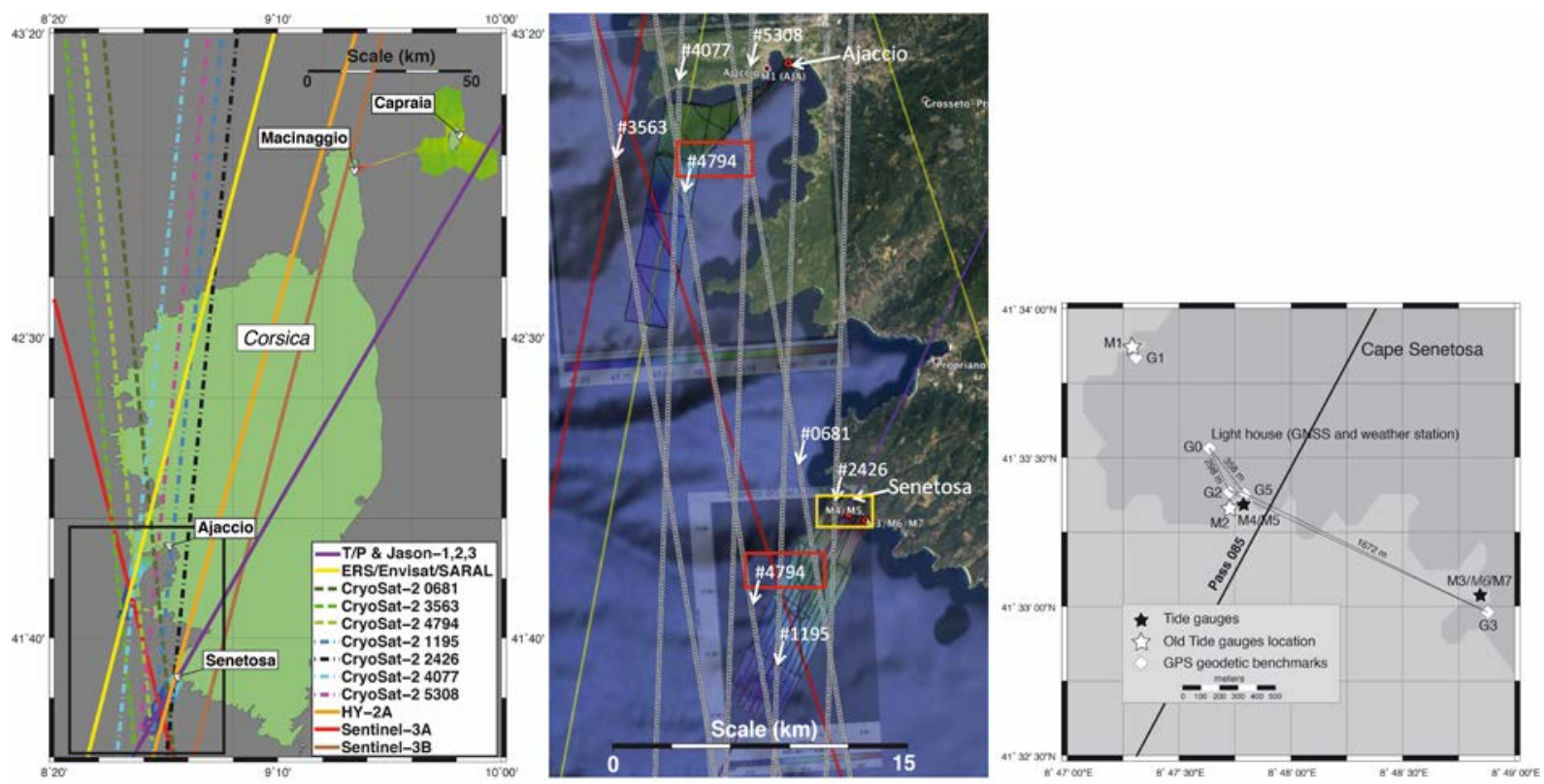

Figure 1. Left: General configuration of the Corsica calibration site with all of the satellite altimeter mission's ground tracks that have been monitored since 1998 (the black frame on the left bottom corresponds to the zoom of the map at the middle). Middle: zoom on Ajaccio and Senetosa sites with the tracks of T/P and Jason (purple), ERS/Envisat and SARAL/AltiKa (yellow), Sentinel-3A (red) and CryoSat-2 (grey). The red rectangles highlight the CryoSat-2 pass \#4794 that crosses the Senetosa and Ajaccio sites (the yellow frame on Senetosa location corresponds to the zoom of the map at the right). Right: zoom on Senetosa showing the locations of the geodetic benchmarks and tide gauges.

\section{Progress on the Geodetic datum}

\subsection{Reference geodetic markers}
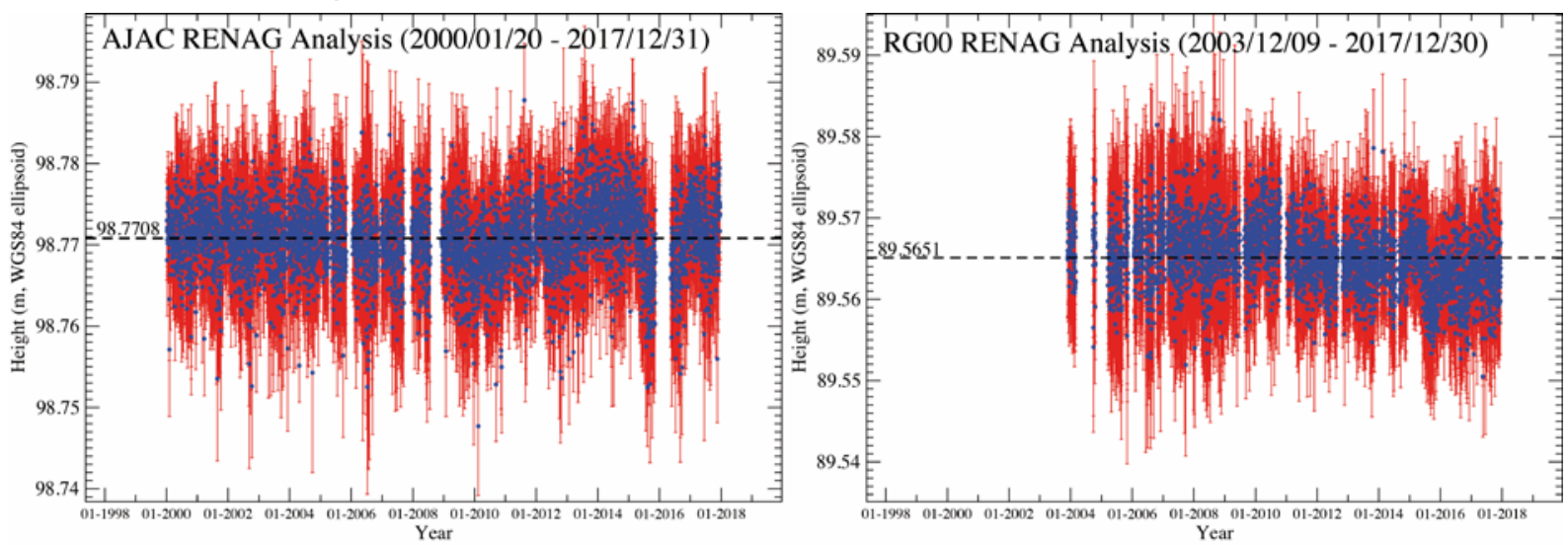

Figure 2. Time series of the up component of the geodetic reference markers at Ajaccio (AJAC, left) and Senetosa (RG00, right).

In the frame of the RENAG project (http://renag.resif.fr) a complete reanalysis of the GPS coordinates has been performed for the Ajaccio (AJAC) and Senetosa (RG00, G0 in Figure 1 
at right) reference markers in the ITRF2014 reference frame. See Nocquet et al. (2016) for details on the processing. In terms of absolute vertical coordinates these new solutions have changed our historical references:

- The vertical coordinate is $98.7708 \mathrm{~m}$ for Ajaccio (AJAC). This height is lower by $-1.5 \mathrm{~mm}$ when compared to our historical reference and by $-0.7 \mathrm{~mm}$ when compared to the ITRF2014 (Altamimi et al. 2016). The very good agreement of these different results permits to have a very great confidence of the vertical component of this reference marker.

- The vertical coordinate is $89.5651 \mathrm{~m}$ for Senetosa (RG00). This height is lower by $-24.2 \mathrm{~mm}$ when compared to our historical reference (and $-4.5 \mathrm{~mm}$ compared to a solution computed recently by JPL with GIPSY over the same period). This clearly shows that there was a $\sim 2 \mathrm{~cm}$ error in our historical reference that was probably due to erroneous values of the antenna phase centers used in 1998 to compute the coordinates of the reference marker at Senetosa (RG00). This was suspected since the installation of a permanent receiver end of 2003 but more clearly since a better robust installation was made in 2009 (notably an autonomous power supply by solar panel and a GPRS communication for data transmission and receiver's handling). Figure 3 illustrates that thanks to this update, the consistency of the SSH biases of the reference altimeters (T/P A\&B, Jason-1/-2/-3) has been improved between the absolute calibration sites of Harvest, Bass Strait and Senetosa (Ocean Surface Topography Science Team meeting, Ponta Delgada, Portugal, 27-28 Sept. 2018).
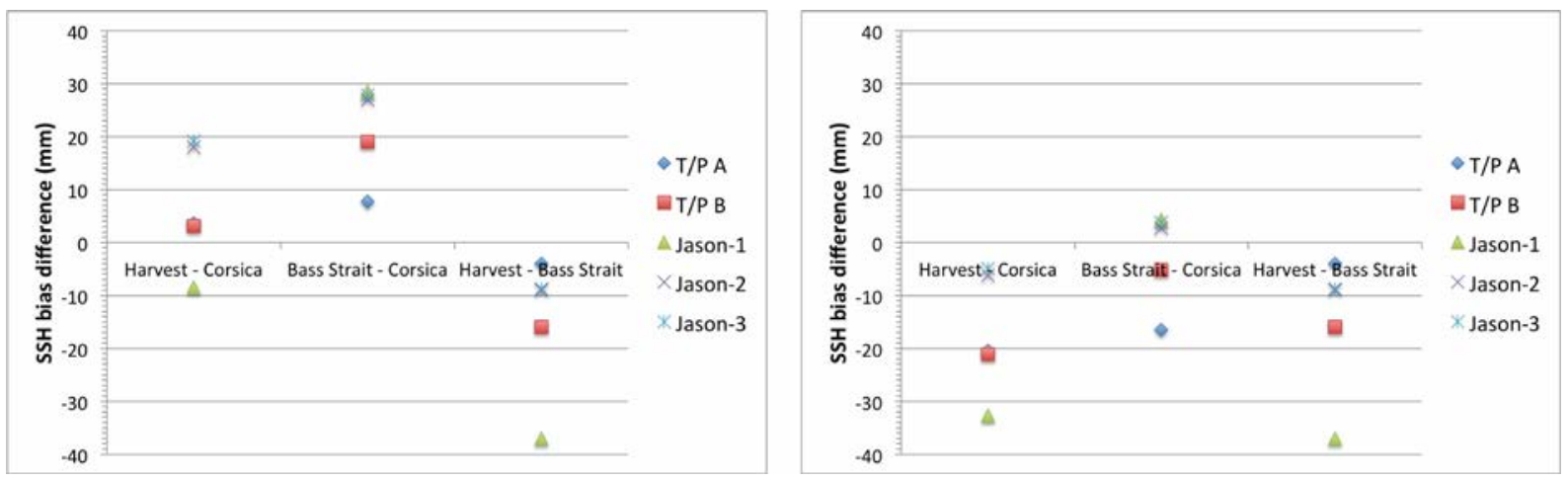

Figure 3. Comparison of the reference missions (TOPEX/Poseidon, Jason-1, Jason-2, Jason-3) SSH biases differences from Bass Strait, Corsica and Harvest before (left) and after applying the up offset $(-24 \mathrm{~mm})$ of the reference marker at Senetosa.

An analysis of the vertical velocities has been conducted using known discontinuities (receiver/antenna upgrades) and some others based on the shapes of the time series (Figure 2) but also by removing an annual signal:

- The vertical velocity is $-0.11 \pm 0.02 \mathrm{~mm} / \mathrm{yr}$ for Ajaccio (AJAC) to be compared to $+0.03 \pm 0.01 \mathrm{~mm} / \mathrm{yr}$ using a simple linear regression and $-0.08 \pm 0.03 \mathrm{~mm} / \mathrm{yr}$ for ITRF2014. The very low values of these different determinations are in agreement with the fact that the value of the vertical component do not change at the millimeter level whatever the solution used (see previous remark)

- The vertical velocity is $+0.28 \pm 0.05 \mathrm{~mm} / \mathrm{yr}$ for Senetosa (RG00) to be compared to $-0.31 \pm 0.01 \mathrm{~mm} / \mathrm{yr}$ using a simple linear regression. The low values and the opposite sign of the two determinations suggest that the vertical velocity of this site is statistically undistinguishable from zero. 
So, the small values of these vertical velocities and the opposite signs at the two locations within a very short distance $(\sim 37 \mathrm{~km})$ suggest that the vertical geophysical motion over this area is very small and thus is difficult to detect at the current level of precision. We then have considered in this study a zero vertical velocity for both sites. Over the whole studied periods, 1998-present for Senetosa and 2000-present for Ajaccio, it would lead to a possible error of respectively $\sim 6 \mathrm{~mm}$ and $\sim 2 \mathrm{~mm}$.

\subsection{Geodetic link with the tide gauge: case of Ajaccio}

At Ajaccio, the SHOM (Service Hydrographique et Océanographique de la Marine) is responsible for the tide gauge (Mors HT200) that was installed in 2000. It was replaced in September 2009 by a Krohne/OPTIFLEX due to aging of the previous system (see details in Bonnefond et al., 2013). In April 2012, it was displaced to a location very close to the previous one (few meters) but higher above sea level allowing measuring higher tides or stronger storm surges. The instrument was also replaced by a Krohne/OPTIWAVE. For each operation (instrument replacement or displacement), but also regularly during maintenance and cleaning, the SHOM performs a leveling relatively to the reference geodetic markers located close in the harbor. The height difference is also measured relatively to the GNSS reference marker (AJAC, see Figure 2 left). As discussed in Bonnefond et al. (2018a), a new processing of all the campaigns provided a much more coherent weighted mean value of the height difference $(50.0371 \mathrm{~m})$, rather than the 2005 reference, with a standard error of the weighted mean of $0.4 \mathrm{~mm}$, thus changing our historical reference by $18.3 \mathrm{~mm}$.

Additionally, during the deployment of the Ajaccio tide gauge in 2012, the SHOM performed SSH observations with a contact gauge and determined a $13.0 \mathrm{~mm}$ bias (standard deviation of $3.6 \mathrm{~mm}$ ) which was introduced as a "calibration offset" into the tide gauge system. A similar bias of $11 \mathrm{~mm}$ was also introduced in the previous tide gauge (2009-2012). No "calibration offset" had been introduced prior to 2009.

We decided to remove this "calibration offset" from the instrument and by adding it to the new leveling correction (of $18.3 \mathrm{~mm}$, see details in Bonnefond et al. (2018a)) and the coordinates update (of $1.5 \mathrm{~mm}$, see section 2.1). Thus, the total systematic error of the tide gauge SSH has been established to $19.8 \mathrm{~mm}$ for the period $2000-2009,30.8 \mathrm{~mm}$ for the period 2009-2012 and $32.8 \mathrm{~mm}$ from 2012 to present (Figure 5). These corrections solved the anomalous SSH bias of $30.5 \pm 4.5 \mathrm{~mm}$ between the Ajaccio tide gauge and our GNSS-based sea level measurements that was identified in Bonnefond et al. (2015).

\subsection{Geodetic link with the tide gauges: case of Senetosa}

The first pressure tide gauge (AANDERAA, WLR7) has been installed in October 1996 at M1 location as a probative experiment (Figure 1, right). In May 1998, two other AANDERAA tide gauges were installed respectively at M2 and M3 locations and M1 was removed. During the 1999 winter, the very big storms over Europe have destroyed one of the tide gauge site (M2). It has been replaced in June 2000 by two tide gauges (M4 and M5) installed in a more protected area, very close together $(<30 \mathrm{~cm})$, in order to better monitor their respective sea level measurements. These new tide gauges have been leveled relatively to a new reference marker (G5, Figure 1 at right and Figure 4). In July 2005, another tide gauge (M6) has been also installed on the other side of the bay very close to M3 $(<30 \mathrm{~cm})$ and leveled relatively to a same reference marker (G3, Figure 1 at right), in order also to monitor their respective sea level measurements. Unfortunately, the mount broke in 2009 and then it was replaced by M7 and leveled relatively to a same reference marker (G3). In 2012, it was decided to replace our AANDERAA tide gauges by those built by the DT-INSU CNRS 
laboratory to improve the accuracy and stability (see section 3.1) but the mounts of the tide gauges were kept in order to preserve the geodetic datum.

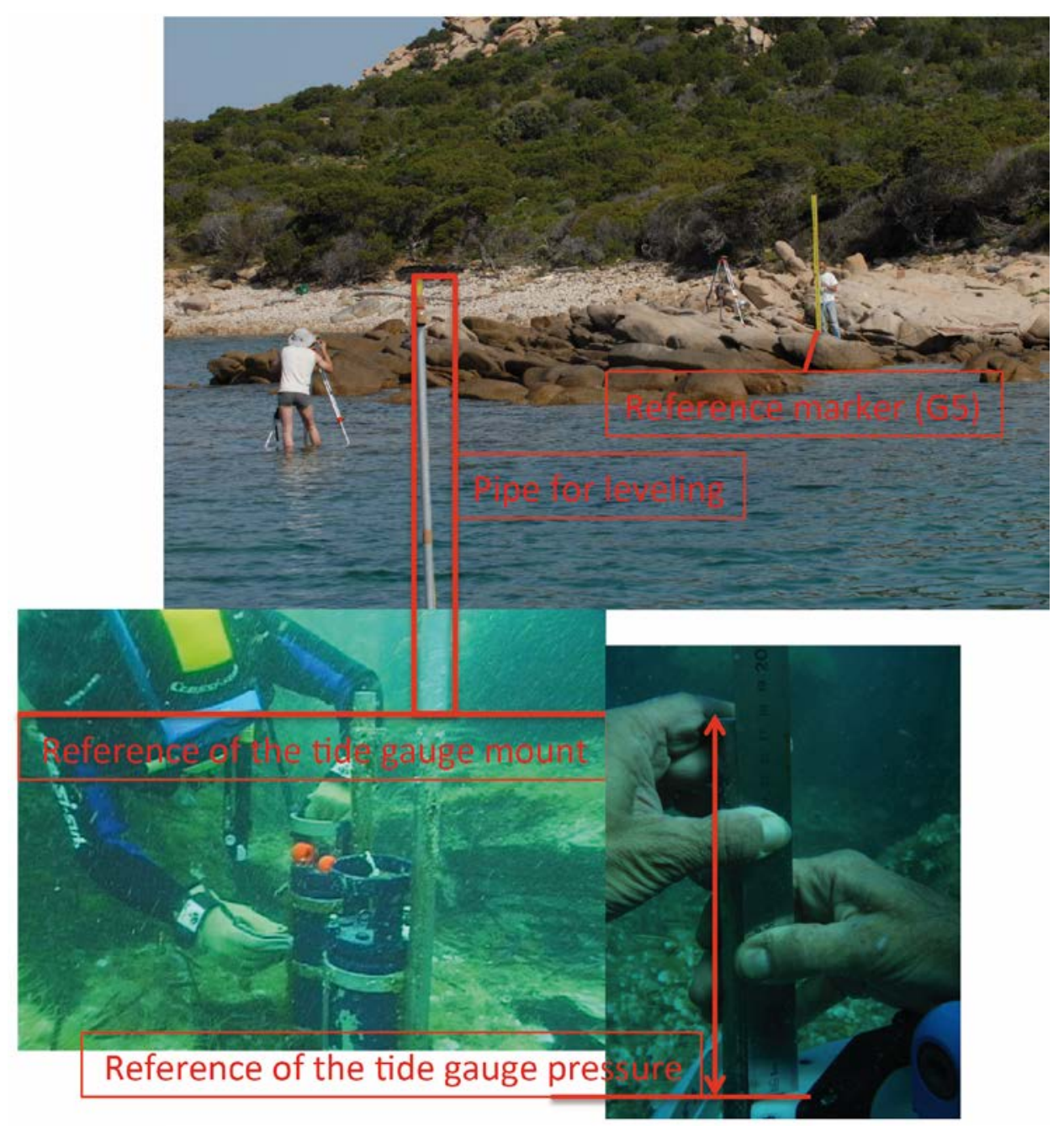

Figure 4. Scheme describing the tide gauge leveling principle.

The principle of the leveling between the tide gauge and a near-by geodetic marker is described in Figure 4 and the results are presented in Table 1. The optical leveling is performed using a pipe with a rule that is inserted in the tide gauge mount. Table 1 shows that this leveling can be achieved with repeatability of less than $1 \mathrm{~mm}$ even after 9 years. In order to measure the vertical position of the tide gauge inside the mount, the diver measures, at each deployment and retrieval, the height between the reference of pressure measurement and the top of the mount that was leveled (Figure 4 at bottom-right). 
Table 1. Leveling of the tide gauges (Mi) relatively to their reference markers (Gi) and between the reference markers themselves in Senetosa (i is the tide gauge or reference marker number).

\begin{tabular}{|c|c|c|c|c|}
\hline & Direct distance (m) & Leveling 2009 (m) & Leveling 1998 (m) & $\begin{array}{c}\text { Differences } \\
\text { /2009 (mm) }\end{array}$ \\
\cline { 3 - 4 } & & & Leveling 2001 (m) & \\
\hline Tide gauges & & & & 0.3 \\
\hline G5 --> M4 & 45 & -4.5166 & -4.5169 & 0.4 \\
\hline G5 --> M5 & 45 & -4.4986 & -4.4990 & 0.8 \\
\hline G3 --> M3 & 32 & -5.2373 & -5.5575 & 0.2 \\
\hline G3 --> M7 & 32 & & -5.5585 & - \\
\hline $\begin{array}{c}\text { Reference } \\
\text { Markers }\end{array}$ & & -3.0531 & - & 0.4 \\
\hline G2 --> G5* & 97 & -38.7550 & -3.0535 & 1.0 \\
\hline G0 --> G2* & 299 & & -38.7560 & \\
\hline
\end{tabular}

*Leveling path: G2 --> G5 = $116 \mathrm{~m}$ and G0 --> G2 $=592 \mathrm{~m}$

Figure 5 gives a synthetic view of all the offsets applied to the in situ SSH as a function of time according to what was explained in sections 2.1,2.2 and 2.3. These values have been used to performed the determination of the SSH biases for all the missions studied in section 4 .

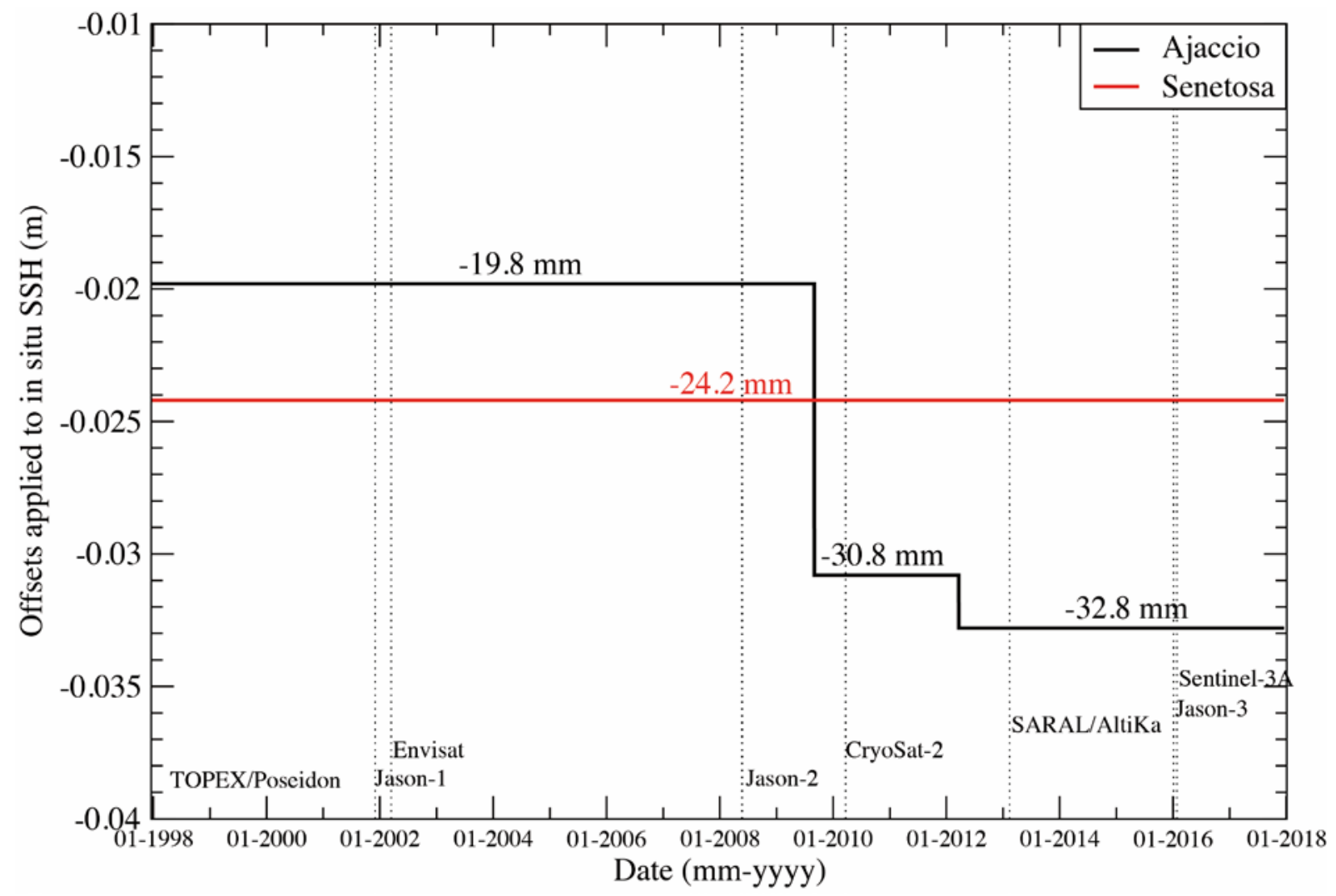


Figure 5. Synthetic view of the offsets applied to the in situ SSH for tide gauges at Ajaccio (black) and Senetosa (red) calibration sites. For GNSS-based sea level measurements only the vertical offsets of the reference markers (AJAC and RG00, see section 2.1) have been applied for the differential kinematic processing. Dot lines indicate the time of launch of the altimetric missions reported here.

\section{LONG-TERM STABILITY OF THE IN SITU INSTRUMENTS}

Along with the accuracy and stability of the geodetic references presented in section 2, another important contribution comes from the accuracy and stability of the sea level measurement systems themselves. This is the purpose of this section and is illustrated through either pressure or radar tide gauges and GNSS-based sea level measurement systems.

\subsection{Pressure tide gauges calibration}

Tide gauges built by the DT-INSU CNRS laboratory (using a Paroscientific pressure sensor 6000-45A) have replaced our AANDERAA tide gauges since 2012. The calibration of the pressure sensors of the tide gauges is performed every $\sim 2$ years by SHOM (Service Hydrographique et Océanographique de la Marine) by comparison with a reference pressure sensor (examples shown in Figure 6) and the results of their behaviors are summarized below:

- The variation as a function of temperature has a negligible slope (below 0.01 mbar $/{ }^{\circ} \mathrm{C}$, Figure 6 top-left) but the value is taken into account to apply the calibration offset at the temperature of each measurement

- The variation as a function of pressure has a negligible slope (below $10^{-4}$ mbar/mbar, Figure 6 bottom-left) but the value is taken into account to apply the calibration offset at the depth of each tide gauge

- The mean offset is around $37 \mathrm{mbar}(\sim 37 \mathrm{~cm}$ of $\mathrm{SSH})$ by construction as it corresponds to the weight of the oil filling the capillary tube and transmitting the water pressure from outside the tide gauge down to the pressure sensor

Table 2 shows a very good stability of the sensors at a few millimeter level and this calibration process allows identifying some important changes that can occur. For example, the very different value of the calibration offset measured in 2013 for M3 was probably due a lack of oil in the capillary tube that connect the pressure sensor to the outside part of the tide gauge that is in contact with the water.
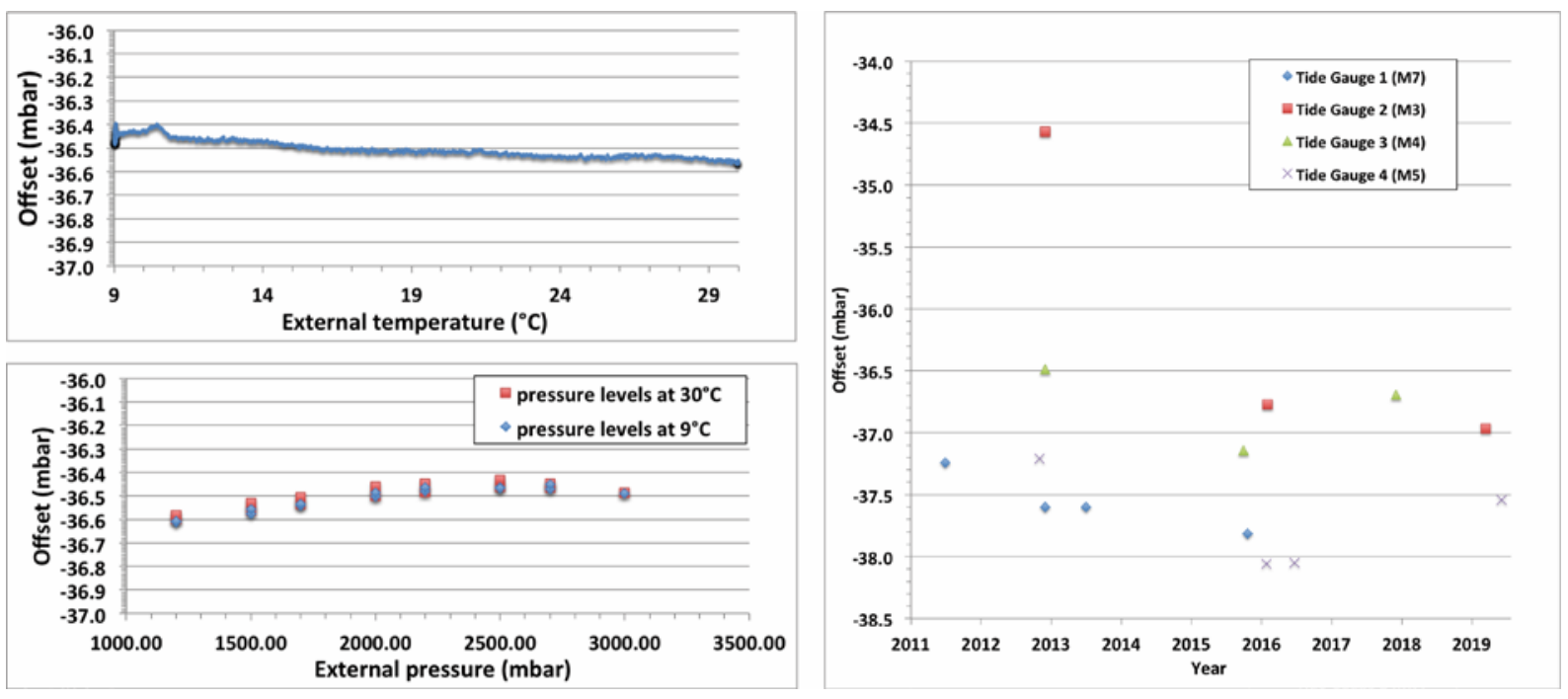
Figure 6. Left: Example of the variations of pressure measurements as a function of temperature (top) and pressure (bottom). Right: Variations of the calibration of the mean offset ( $\sim 37$ mbar by construction) over the last 6 years for the Senetosa tide gauges.

Table 2. Mean offset's values for the four tide gauges used in Senetosa

\begin{tabular}{|l|c|c|}
\hline & Mean (mbar) & $\sigma$ (mbar) \\
\hline Tide Gauge 1 (M7) & -37.56 & 0.24 \\
\hline Tide Gauge 2 (M3) & -36.10 & 1.33 \\
\hline Tide Gauge 3 (M4) & -36.77 & 0.33 \\
\hline Tide Gauge 4 (M5) & -37.63 & 0.59 \\
\hline
\end{tabular}

\subsection{Radar tide gauge calibration}

At Ajaccio, at least once a year, we perform SSH observations with a contact gauge that is inserted in the stilling well and compare them to radar measurement (Figure 7). For each session of control, the SHOM protocol is:

- (1) make one measurement every $15 \mathrm{~s}$ during $2 \mathrm{~min}$.

- (2) reproduce the sequence (1) every $10 \mathrm{~min}$ during $1 \mathrm{~h}$

- Make sequences (1) and (2) at low tide and high tide during the day of control

For each session of control, the standard deviation of the differences is of $2.7 \mathrm{~mm}$ on the average. Over all the control sessions performed since 2012 (new tide gauges were installed), the average difference with the tide gauge measurements is $+2.3 \mathrm{~mm}$ with a standard deviation of $2.5 \mathrm{~mm}$.
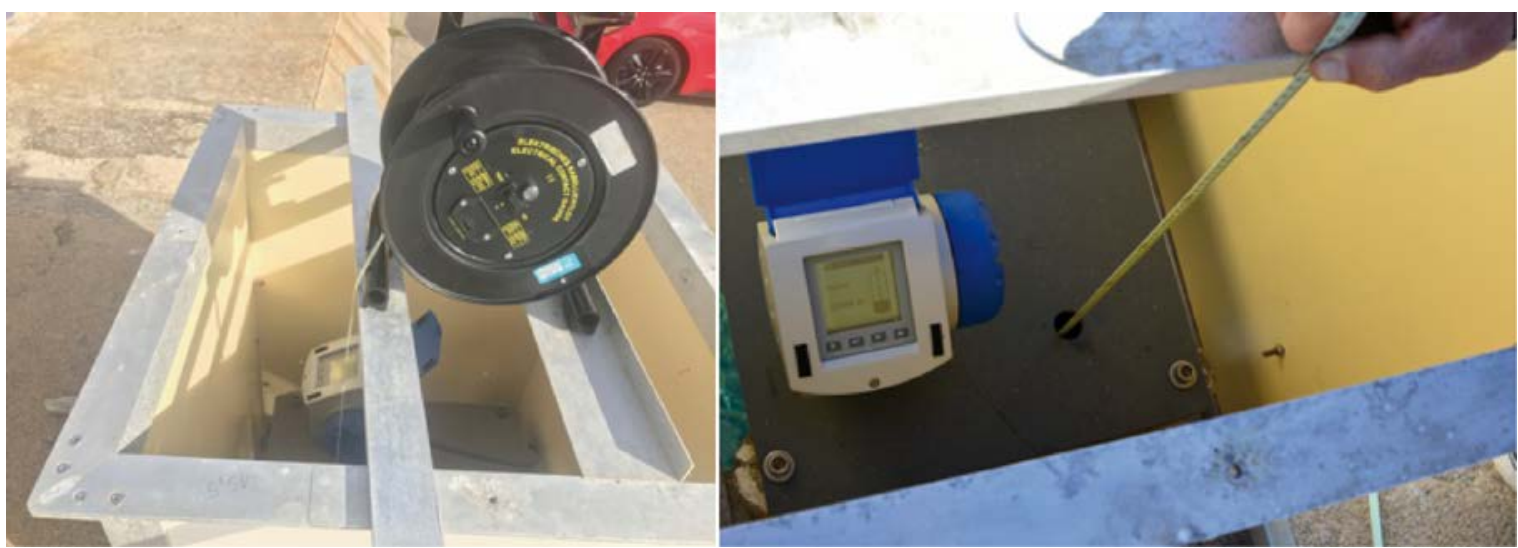

Figure 7. Control of the Ajaccio radar tide gauge using a contact probe. 


\subsection{Comparisons with independent measurements}

- M3SENE-M4SENE - M3SENE-MSSENE M4SENE - MSSENE - MSSENE-M7SENE - M4SENE-MSSENE - M1SENE-M2SENE - M1SENE-M3SENE - M2SENE-M3SENE

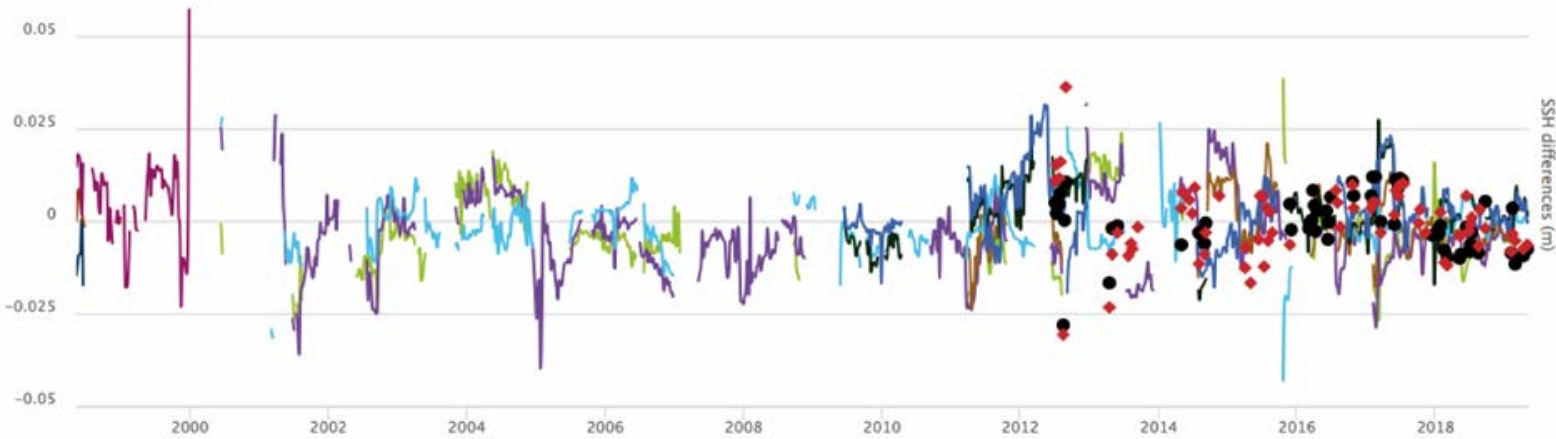

Figure 8. Time series of the SSH differences between Senetosa tide gauges (MiSENE where $i$ is the tide gauge number and SENE is the abbreviation of Senetosa). The black dots and red diamonds correspond to the SSH differences with our GNSS-based sea level measurement system.

Table 3. Statistics of the SSH differences between tide gauges themselves (Mi where $i$ is the tide gauge number) and between GNSS-based sea level measurement system (GPS) and tide gauges at Senetosa. The distances between the instruments are indicated in brackets.

\begin{tabular}{|c|c|c|c|c|}
\hline Type of comparison (distance) & Mean (mm) & $\sigma(\mathbf{m m})$ & Drift (mm/yr) & Number of data* \\
\hline Between tide gauges (since 2001) & & & & \\
\hline M3 - M4 ( 1.7 km) & -2.3 & 10.9 & $-0.07 \pm 0.02$ & 10184 \\
\hline M3 - M5 ( 1.7 km) & -3.6 & 12.0 & $+0.07 \pm 0.02$ & 16357 \\
\hline M7 - M4 ( 1.7 km) & -2.6 & 9.9 & $-0.29 \pm 0.04$ & 6711 \\
\hline M7 - M5 ( 1.7 km) & -3.0 & 10.6 & $-0.15 \pm 0.04$ & 8590 \\
\hline M3 - M7 ( -0.3 m) & -0.3 & 8.2 & $-0.06 \pm 0.05$ & 6046 \\
\hline M4 - M5 ( 0.3 m) & -0.9 & 7.1 & $+0.05 \pm 0.01$ & 13026 \\
\hline $\begin{array}{l}\text { Between GPS and tide gauges (since } \\
\text { 2012) }\end{array}$ & & & & 64 \\
\hline GPS - M4 (less than 200m) & -0.6 & 7.7 & $-0.28 \pm 0.47$ & \\
\hline GPS - M5 (less than 200m) & -0.5 & 9.4 & $-0.28 \pm 0.52$ & \\
\hline
\end{tabular}

*For the tide gauges statistics, the time series (Figure 8 ) are subsampled to $6 \mathrm{hr}$ instead of their native sampling of $10 \mathrm{~min}$

Over a period of more than 20-yr, we have analyzed the SSH differences by pair between the tide gauges deployed at Senetosa since 2001 (Figure 8). As a result, the averaged differences are at the few millimeters level with $\sim 10 \mathrm{~mm}$ standard deviation (Table 3). Moreover, the stability of the differences is globally better than $\sim 0.1 \mathrm{~mm} / \mathrm{yr}$ (over now more than 17 years for some time series). Finally, when two tide gauges are very close together (M4 and M5 or $\mathrm{M} 3$ and M7), the standard deviation is clearly lower than $1 \mathrm{~cm}(7.1 \mathrm{~mm}$ and $8.2 \mathrm{~mm}$, 
respectively). On the other hand, when the distance is longer (see Figure 1), the standard deviation is increasing to more than $10 \mathrm{~mm}$ (see for example M3-M4 and M3-M5 in Table 3). Thus, it reveals that, even at relatively short distance $(\sim 1.7 \mathrm{~km})$, local conditions can made the sea level different at the few millimeters level in term of standard deviation.

We also use our GNSS-based sea level measurement system regularly to achieve some comparisons with the tide gauges. This is done at the time of each deployment and retrieval of the tide gauges at Senetosa (about every 3-4 months) but also for some Jason overflights. The results presented in Table 3 show also a very good consistency at the millimeter level. The drift between both determinations is relatively large but not significant because of the short time series (6 years) and, more importantly, because the GNSS-based sea level measurements are not continuous (few determinations by year not evenly distributed).

The fact that this independent GNSS-based system is used for both the Ajaccio and Senetosa sites allows us to cross compare the accuracy of their tide gauges. As discussed in section 2.2 but also discussed in Bonnefond et al. (2015 and 2018), these comparisons have permitted to detect the $3 \mathrm{~cm}$ offset with an accuracy of $\pm 4.5 \mathrm{~mm}$ (standard deviation) for the Ajaccio tide gauge measurements, while no clear offsets were detected for the ones of Senetosa (Table 3). We must precise that the GNSS processing is done in relative mode using the reference receiver at each site; so the offsets given in section 2 affect the vertical position of both the tide gauge and the GNSS-based system sea level measurement system in the same way.

\section{SSH BIASES OF ALTIMETRIC MISSIONS}

Determining the absolute altimeter bias requires the Sea Surface Height (SSH) measurement to be performed in a terrestrial reference system comparable to the altimetry system at a

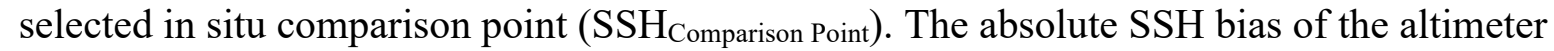
(BiasAlt) can then be determined using the simple relation:

Bias Alt $=\mathrm{SSH}_{\text {Alt }}-\mathrm{SSH}_{\text {ComparisonPoint }}(1)$

Where $\mathrm{SSH}_{\text {Alt }}$ is derived from altimetric measurements and $\mathrm{SSH}_{\text {Comparison Point }}$ from in situ measurements

$\mathrm{SSH}_{\mathrm{Alt}}=\mathrm{h}-\left(\mathrm{R}+\Delta \mathrm{R}_{\mathrm{DRY}}+\Delta \mathrm{R}_{\mathrm{WET}}+\Delta \mathrm{R}_{\mathrm{ION}}+\Delta \mathrm{R}_{\mathrm{SSB}}+\Delta \mathrm{R}_{\mathrm{GEO}}\right)(2)$

Where:

$\mathrm{h}$ is the height of the center of mass of the satellite above the reference ellipsoid, determined from precise orbits (POD);

$\mathrm{R}$ is the nadir distance measurement from the center of mass of the satellite to the sea surface;

$\Delta \mathrm{R}_{\mathrm{DRY}}$ is the delay due to atmospheric refraction caused by the dry component of the troposphere;

$\Delta \mathrm{R}_{\text {WET }}$ is the delay due to atmospheric refraction caused by water and the liquid water vapor content of the troposphere;

$\Delta \mathrm{R}_{\mathrm{ION}}$ is the delay caused by the free electron content of the ionosphere. Due to the noise of this correction, when derived from a dual-frequency altimeter, it is averaged over $140 \mathrm{~km}$ ( 20 s) along track (Imel, 1994 and Jason-3 Products Handbook (https://www.aviso.altimetry.fr/fileadmin/documents/data/tools/hdbk_j3.pdf)); 
$\Delta \mathrm{R}_{\mathrm{SSB}}$ is the sea state bias correction, and

$\Delta \mathrm{R}_{\mathrm{GEO}}$ is the sum of the solid tide, loading tide and pole tide corrections.

A negative bias therefore indicates a sea level measured by the altimeter that is too low (i.e., a distance measurement that is too long or a satellite altitude that is too low).

Two distinct approaches exist for the in situ measurement of SSH at the point of comparison

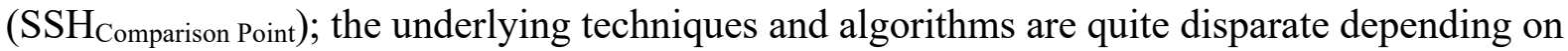
the particular application and will not be developed here (see Bonnefond et al. 2011 and 2015 for details). They generally consider, either directly or indirectly, geophysics, oceanographic and atmospheric phenomena that cause spatial and temporal variations in sea levels:

- Direct approach: In this case, the SSH is physically observed at the point of comparison. In the case of the NASA calibration site at Harvest (Haines et al., 2003), the platform itself (with the associated sea level instrumentation) is located at the point of comparison, allowing direct estimation of the SSH for each flyby. Studies using only buoys equipped with GNSS are other examples of this direct calibration methodology (see Bonnefond et al. (2015) and section 4.3).

- Indirect approach: In this case, SSH measurement involves observing sea level away from the point of comparison, typically using a nearby tide gauge. The remote $\mathrm{SSH}$ is then "transferred" or "extrapolated" offshore through the use of local high-resolution geoid models (Bonnefond et al., 2003a), and using also in many cases, numerical tidal and atmospheric forcing models. Examples include the calibration site in Corsica (Bonnefond et al., 2003b), the UK project (Woodworth et al., 2004), and the Greek project in Gavdos (Mertikas et al., 2018). The indirect technique offers logistical advantages, while maintaining the ability to determine the absolute bias cycle by cycle. The accuracy of the SSH transfer technique (i.e. the accuracy of geoid and tides models) is the limiting factor of this methodology (Watson et al., 2004). The differential effects of tides and atmospheric pressure must also be taken into account in the error budget. The magnitude of these effects depends not only on local conditions (for example, the shape of the coast, bathymetry), but also on the distance over which the SSH is transferred. Tidal models and atmospheric pressure are not used in Corsica because the estimated impact, even using high-resolution models, is at the level of a few millimeters over the considered area (Cancet et al., 2013). Thus, the corrections for ocean tide, inverted barometer and the high frequency wind and pressure response are not applied to the altimetry measurements in equation (2) nor to the in situ ones because the signal is supposed to be identical. So only the Sea Surface Heights differences between the altimetric measurement locations and the comparison point location (tide gauges) is computed and applied using the geoid maps: the first SSH is computed from the contour maps (geoid) shown in Figure 1 (left and middle) and the latter is a constant given in Table 4 (details of the processing can be found in Bonnefond et al. (2003a and 2003b)).

These two approaches will be illustrated in the case of SARAL/AltiKa (section 4.3) while only the indirect approach will be shown for all other missions presented here. The products and main parameters for the SSH biases computation described in this section are given in Table 5.

Table 4. Mean of GPS sea heights at tide gauges location (relatively to WGS84, in m)

\begin{tabular}{lll}
\hline Site & Tide gauge location & Mean height $(\mathrm{m})$ \\
\hline Senetosa (1999 campaign) & M3/M6/M7 & 47.4216 \\
& M2/M4/M5 & 47.3635 \\
\hline Ajaccio (2005 campaign) & M1 & 47.8898 \\
\hline
\end{tabular}


Table 5. Summary of the products and corrections used for SSH biases determination. For all the missions $\Delta \mathbf{R}_{\mathrm{DRY}}$ (dry tropospheric correction) and $\Delta \mathbf{R}_{\mathrm{GEO}}$ (sum of the solid tide, loading tide and pole tide corrections) are also used from the products

\begin{tabular}{|l|l|l|l|}
\hline Mission & Product & Ionospheric correction & Wet tropospheric correction \\
\hline T/P (ALT-A\&B) & MGDR++* & Dual-frequency & Radiometer \\
\hline Jason-1 & GDR-E & Dual-frequency & Radiometer \\
\hline Jason-2 & GDR-D & Dual-frequency & Radiometer \\
\hline Jason-3 & GDR-T & Dual-frequency & Radiometer \\
\hline ERS-2 & REAPER & GIM model & ECMWF model \\
\hline Envisat & FMRV3 & GIM model & ECMWF model \\
\hline CryoSat-2** & GPOD baseline C & GIM model & ECMWF model \\
\hline SARAL/AltiKa & GDR-T & GIM model & ECMWF model \\
\hline Sentinel-3A & PDGS & Dual-frequency & Radiometer \\
\hline Sentinel-3B & PDGS & Dual-frequency & Radiometer \\
\hline
\end{tabular}

*Merged Geophysical Data Record but using the TMR (radiometer) replacement products and the std0905 orbits (GSFC)

**No Sea State Bias correction was provided by GPOD so 3.5\% of Significant Wave Height was used

\subsection{Reference missions (TOPEX/Poseidon, Jason-1, Jason-2, Jason-3)}

The Senetosa calibration facilities have been initially developed to monitor the performance of TOPEX/Poseidon and to follow the Jason legacy satellite altimeters. This site provides more than 20 years of SSH observations for these missions (Figure 9). As discussed in sections 2 and 3, a particular care has been taken to insure the stability of the geodetic datum and the instruments' measurements. Because the time series are composed of only one determination every ten days, it is however difficult to derive any drift of the altimeters' SSH biases, even over several years. The linear trend values in Figure 9 are thus given only for information and are not statistically significant. On the other hand, the mean values of the SSH biases are determined with a high level of confidence with a standard error of few millimeters ( $2 \mathrm{~mm}$ for the longer time series of Jason-2). The mean SSH biases range from -11 (Jason-3) to $+43 \mathrm{~mm}$ (Jason-1) with a standard deviation of $18 \mathrm{~mm}$ : this shows that inter-mission biases still exist at the level of several centimeters and this reinforces the need of tandem verification phase between consecutive missions to insure the consistency of the climate record of these reference missions (Fu and Haines, 2013).

The very high resolution of the geoid's map, up to the tide gauges locations, determined in 1999 also allows us to estimate the impact of the land contamination on the altimeter range. Such study published in Bonnefond et al. (2013) has shown that from $10 \mathrm{~km}$ to the coast the impact is at the level of $8 \mathrm{~mm} / \mathrm{km}$ so the SSH biases presented here are limited to altimeter data at more than $10 \mathrm{~km}$ from the coast.

In terms of land contamination, one other source of error comes from the radiometer and it affects its measurement far from the coast due to the larger size of its footprint (radius of 25$50 \mathrm{~km}$ for Jason class satellites). Thanks to the wet tropospheric corrections determined from our reference GPS, the same study has permitted to quantify this contamination (up to tens of $\mathrm{mm}$ ) and to validate the Enhanced Path Delay (EPD) product developed by Brown (2010) that are now included in the Geophysical Data Record (GDR). This improved correction permits to use the radiometer corrections without significant bias (less than $8 \mathrm{~mm}$ ) within $15 \mathrm{~km}$ from the coast. 


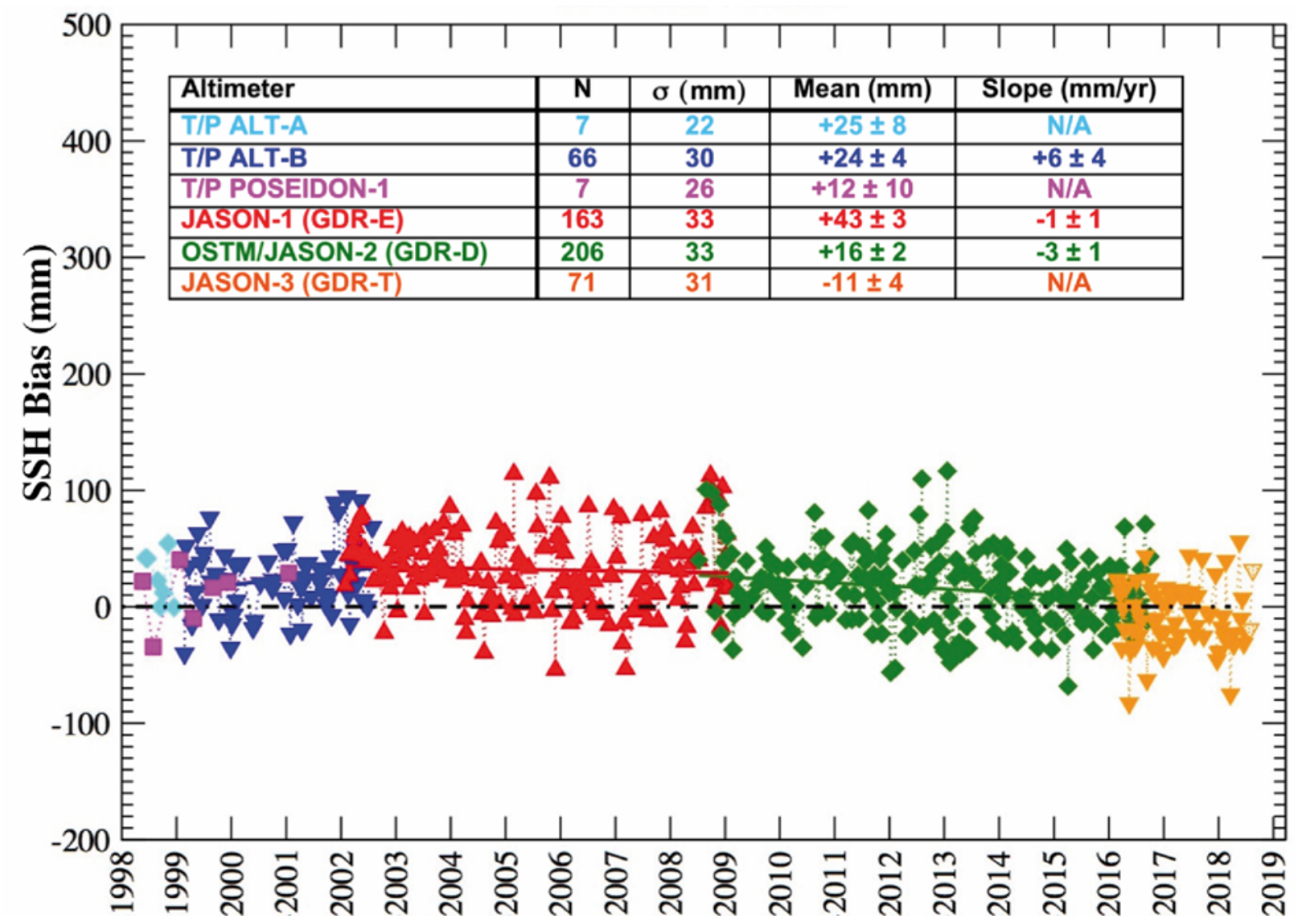

Figure 9. SSH biases time series for the reference missions (TOPEX/Poseidon, Jason-1, Jason-2, Jason-3).

\subsection{ERS-2 and Envisat}

In 2005, in addition to the historical site at Senetosa, we developed the Ajaccio site to enable the monitoring of the ESA ERS-2 and Envisat missions. The determination of the geoid under the \#130 ground track has allowed us transferring the offshore altimetric measurements to the sea level measurements performed by the tide gauge which was installed in the harbor of the Aspretto's military base in 2000. By assuming a constant local geoid shape, is has been possible to monitor the SSH of the ERS-2 mission back to 2000.

For ERS-2, the data used are from the REAPER reprocessing (Brockley et al., 2017) and for Envisat, the data used are from the Full Mission Reprocessing (FMR) campaign completed in 2018 (RA-2/MWR Level 2 V3.0 dataset). For consistency between ERS-2 and Envisat, we have chosen to use the wet tropospheric correction from the ECMWF model and the ionospheric one from the GIM model. Indeed, during the REAPER reprocessing the radiometer correction was not fully validated and will be updated in a future reprocessing. Concerning the ionospheric correction, because the Envisat S-band of the altimeter was lost during cycle 65 (January 2008), we decided to use the GIM model for both ERS-2 and Envisat processing.

The SSH bias time series for both ERS-2 and Envisat are illustrated in Figure 10 (left and right respectively). In comparison with the other missions studied here, the mean SSH biases for both missions are relatively large (673 and $491 \mathrm{~mm}$ respectively) suggesting that a constant error (e.g. internal path delay) still remains in the recent reprocessing, despite important efforts that have been made by the project teams to understand its origin. The standard deviation of ERS-2 SSH bias is also relatively large $(70 \mathrm{~mm})$ compared to other missions (more often around $30 \mathrm{~mm}$ ) but the Ajaccio tide gauge was installed in 2000 so the 
studied period is only for the latest period of ERS-2 REAPER reprocessing when the satellite encountered some outages (loss of the last gyroscope in January 2001 and failure of the onboard tape storage system in June 2003). Moreover there's a large data gap for the Ajaccio tide gauge between 2001/01/25 (cycle 60) and 2002/02/16 (cycle 72).
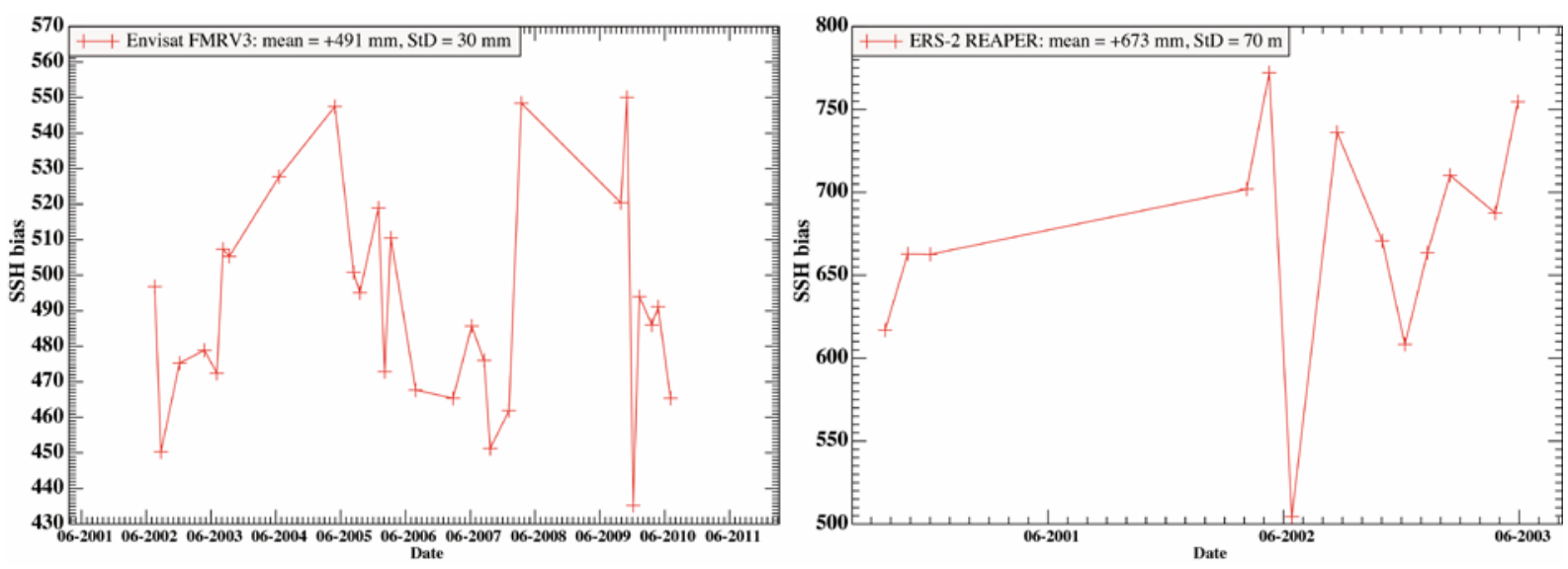

Figure 10. SSH biases time series for ERS-2 (left) and Envisat (right)

\subsection{SARAL/AltiKa}

SARAL/AltiKa, launched in February 2013, was intended to be a gap filler mission between Envisat and Sentinel-3 and, consequently, it flies on the same orbit as Envisat. However, this new satellite not only provides a continuation of the ERS-Envisat time series but also provides a new technology: the AltiKa instrument is a Ka-band altimeter and has an embedded dual-frequency radiometer. The enhanced band-width $(35.75 \mathrm{GHz}, 500 \mathrm{MHz})$ provided by the single frequency Ka-band altimeter leads to a better vertical resolution as well as improving the spatial resolution thanks to the Ka-band's smaller footprint. Then, the Ajaccio calibration site has allowed us to monitor SARAL/AltiKa by still using the same approach. The choice of using the ECMWF model instead of the radiometer's wet tropospheric correction was made to be consistent with the analysis of ERS-2 and Envisat. Moreover, the correction GDR-T (T as "Test") was preliminary and will be upgraded in the next release (GDR-E is planned to be released in the coming months). However, we have also analyzed the radiometer's wet tropospheric correction and the results show a difference (radiometer - model correction) of $+11 \mathrm{~mm}$ with a standard deviation of $19 \mathrm{~mm}$. When compared to the wet correction derived from the Ajaccio GPS receiver the difference is $-2 \mathrm{~mm}$ with the same standard deviation of $19 \mathrm{~mm}$. The first results published in Bonnefond et al. (2015) have demonstrated that the mission improves the coastal measurements as close as 3-6 km. It has been seen through a higher number of data available and a much lower land contamination in comparison to Envisat (same ground track). A particular effort has been made for monitoring SARAL/AltiKa with the deployment of our GNSS-based sea level measurement system (GPS-zodiac, see Figure 11 at bottom right) as often as possible when the sea conditions have permitted to do it in safe conditions. The objective was to cross compare the direct and indirect approaches described in the beginning of section 4 . The direct approach has permitted us to make measurements even during the period when the difficulties with the satellite reaction wheels did not permit the ground track to be accurately maintained (from March 2015 until the Drifting Phase in July 2016). This is illustrated in Figure 11 (bottom maps) for three cycles $(24,25$ and 35) when the satellite was too far from the nominal ground track and did not overflight the geoid map. As a result of the direct approach, the SSH biases (bold red circles in Figure 11) are consistent with the rest of the time series. Since the beginning of the Drifting Phase, SARAL/AltiKa has overflown both Corsica calibration sites 
(Ajaccio and Senetosa) in different configurations (see the right part of Figure 11). The SSH biases have then been computed using Senetosa or Ajaccio tide gauges or even both when the satellite have overflown both areas (shaded in purple on Figure 11 maps). The derived SSH biases (bold blue crosses in Figure 11) are also consistent with the rest of the time series.

In summary, using either the indirect (tide gauges) or direct (GPS-zodiac) calibration approaches gives similar SSH bias, respectively $-67 \pm 5 \mathrm{~mm}$ and $-68 \pm 11 \mathrm{~mm}$. Even during the Drifting Phase, we can continue to monitor the SSH bias every 36 days in average (not evenly distributed in time and location) compared to the 35-day repeat period during the nominal phase.

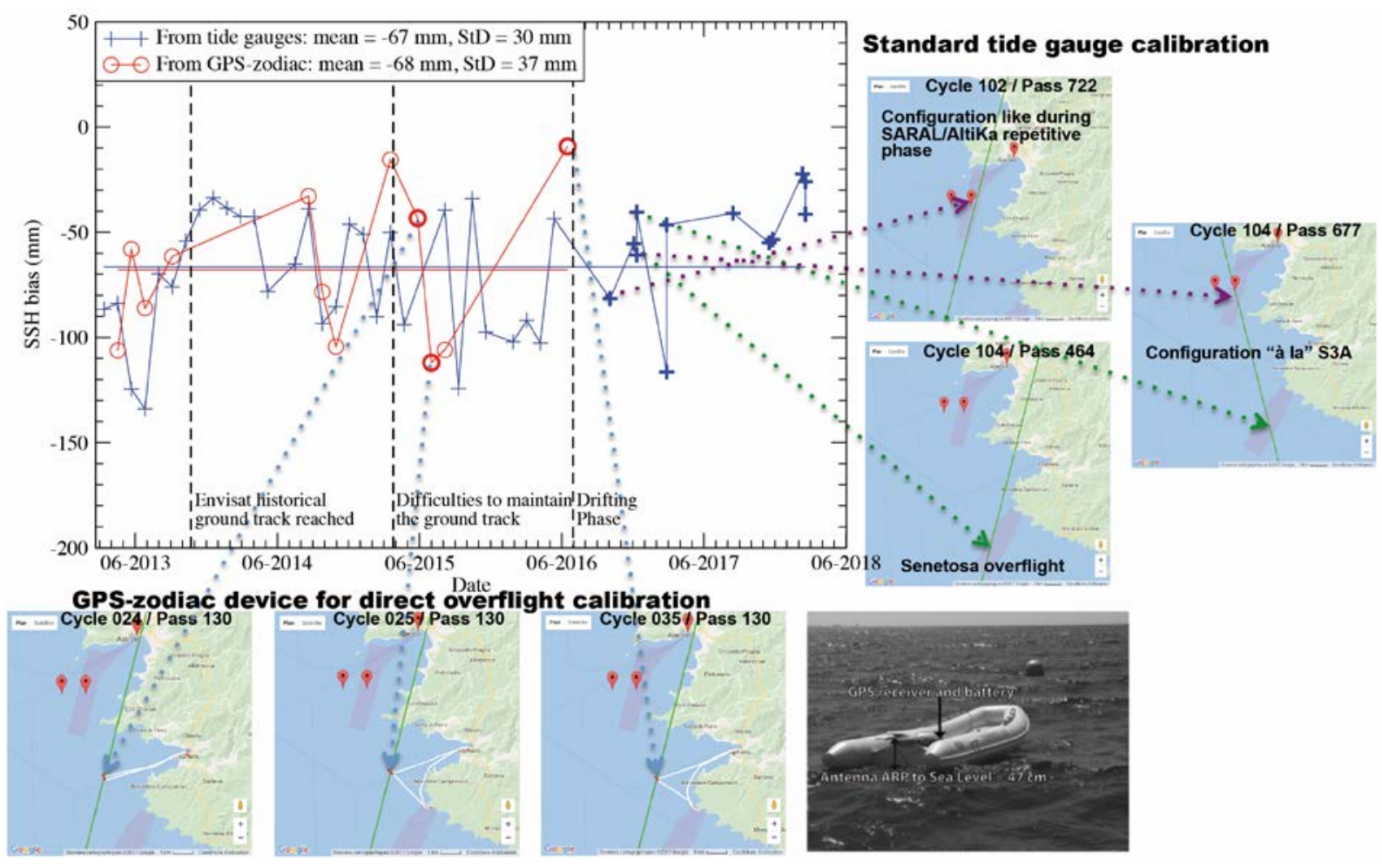

Figure 11. Sea Surface Height (SSH) bias time series for SARAL/AltiKa over Corsica for both direct (GPS-zodiac, red circles) and indirect (tide gauges, blue crosses) approaches. The bold symbols correspond to situations where the satellite was not overflying the calibration sites in a nominal configuration.

\subsection{CryoSat-2}

A detailed study of Cryosat-2 has been recently published in Bonnefond et al. (2018). We will only summarize here the main results. Over the Corsica area, CryoSat-2 being in the Synthetic Aperture Radar (SAR) mode it was then particularly interesting to cross-compare results with Sentinel-3A. The data used are from SARvatore service at ESA G-POD (https://gpod.eo.esa.int/services/CRYOSAT_SAR/) and the difference compared to the previous published study comes from the use of the baseline $\mathrm{C}$ products, the main difference being the correction of a known range bias of $673 \mathrm{~mm}$. The CryoSat-2 altimeter passes overfly the Senetosa or Ajaccio facilities or both (see Figure 1 middle). The ground track \#4794 is particularly interesting because it overflights Senetosa and Ajaccio sites in a similar situation than the one of Sentinel-3A; it allows us to verify the consistency of the geodetic datum for both sites. The time series of the SSH biases computed from both sites for all the CryoSat-2 passes in the area are presented in Figure 12. The average value of the SSH bias for all passes is $+5 \pm 8 \mathrm{~mm}$ for Ajaccio and $+8 \pm 5 \mathrm{~mm}$ for Senetosa showing the great 
consistency of both geodetic datum. The mean value of all the SSH bias (Ajaccio and Senetosa) is $+7 \pm 4 \mathrm{~mm}$.

Another important point is that our result looks coherent with the Svalbard transponder result also based on baseline C products (Garcia-Mondejar et al, 2018) of $-39 \mathrm{~mm}$ (opposite sign to convert from range to SSH bias). It is worth noting that the $46 \mathrm{~mm}$ remaining difference between these two determinations can be due to the geophysical corrections, and notably the SSB that is not affecting the transponder processing. We recall that we are using a simple SSB correction $(3.5 \%$ of SWH).

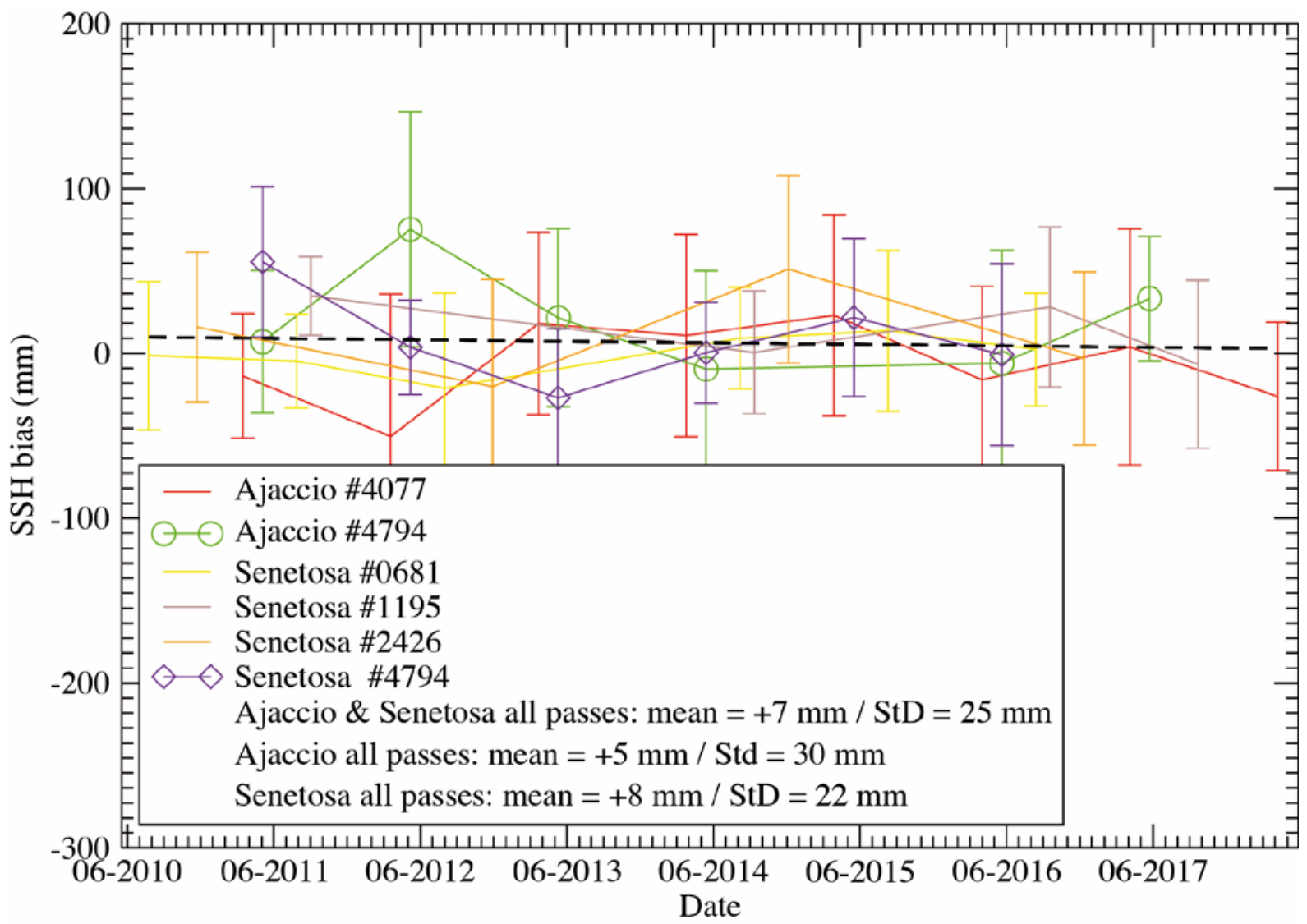

Figure 12. SSH biases time series for CryoSat-2 (baseline $\mathrm{C}$ products) at Ajaccio and Senetosa 


\subsection{Sentinel-3A and Sentinel-3B}
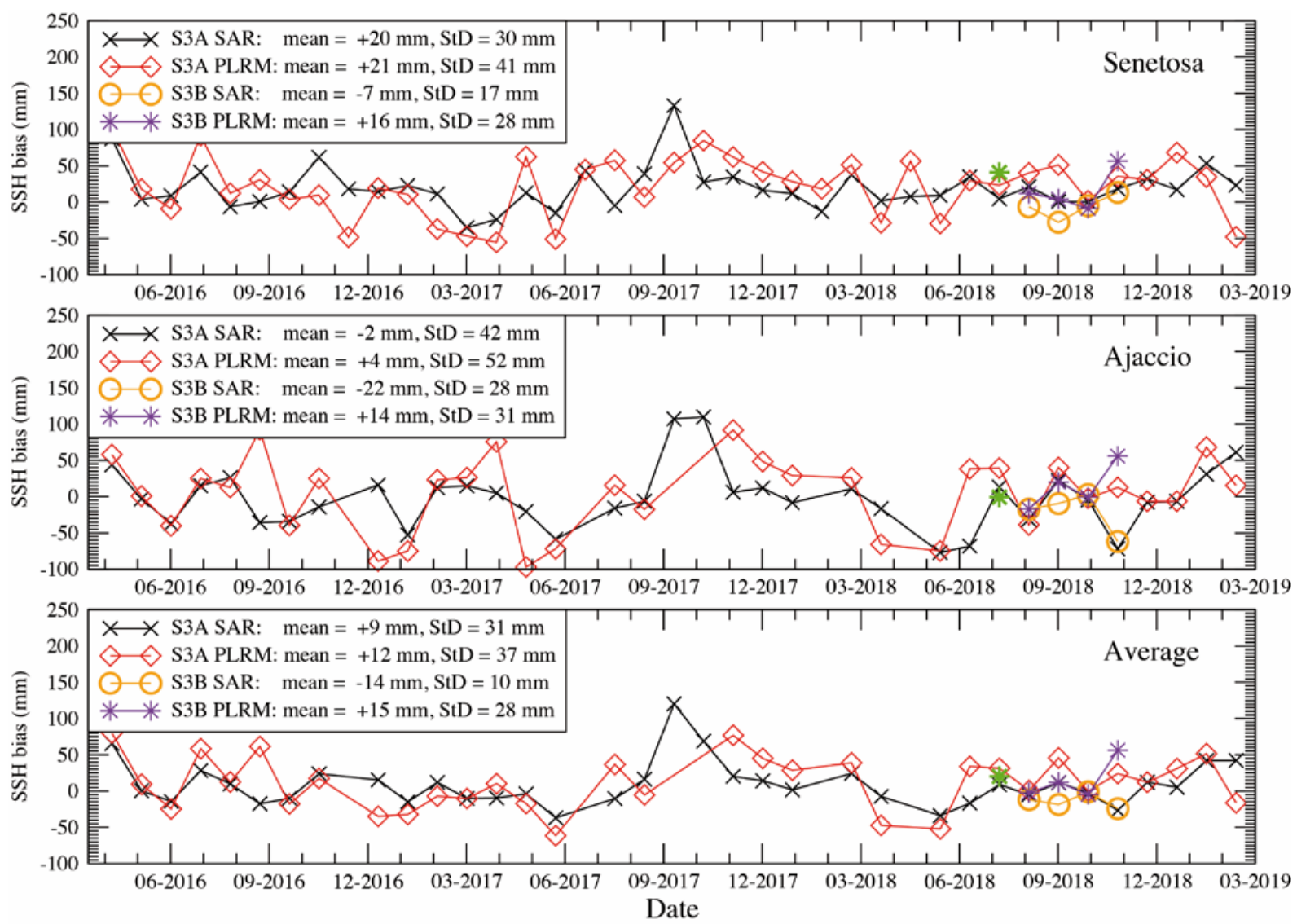

Figure 13. SSH biases time series for Sentinel-3A (S3A) and Sentinel-3B (S3B) in SAR and PLRM modes. The first cycle of Sentinel-3B was in real LRM (green star).

As already mentioned for Cryosat-2, the same detailed study of Bonnefond et al. (2018) does contain Sentinel results; so we will only give an update from recent cycles that have been included for Sentinel-3A and Sentinel-3B. The data used come from the S3-PDGS (Payload Data Ground Segment) reprocessing (2017) using the Non-Time Critical (NTC) products, followed by the data processed with the same standards. The products used for Sentinel-3B are inline with the Sentinel-3A ones. Sentinel-3B was launched on April, 252018 and had a tandem phase with Sentinel-3A from June 2018 (cycle 9) until October 2018 (cycle 13) with a $30 \mathrm{~s}$ separation. In order to cross-compare with Sentinel-3A SAR measurements, the cycle 9 of Sentinel-3B was operated in LRM (Low Resolution Mode) Closed Loop mode.

The Sentinel-3A ascending pass \#741 overflies the Senetosa site and the Ajaccio one $\sim 5 \mathrm{~s}$ later. As already shown for CryoSat-2 (section 4.4), this allows us to compare the SSH biases, which can be independently determined at both locations, and then to assess geodetic references together with in-situ measurements. Figure 13 shows the time series of Sentinel-3A and Sentinel-3B for Senetosa (top), Ajaccio (middle) and the average of both sites (bottom). The times series are given for the two modes that are used to derive the sea surface height from the radar measurements: (i) the SAR (Synthetic Aperture Radar) mode and (ii) the PLRM (pseudo LRM) mode that mimics the classic LRM. The independent results obtained from Senetosa and Ajaccio show a difference in the SSH bias of respectively 22 and $17 \mathrm{~mm}$ (Senetosa minus Ajaccio) for the SAR and PLRM modes, respectively. The results summarized in Table 6 for CryoSat-2, Sentinel-3A and Sentinel-3B in SAR mode can be explained by a difference of behavior of both altimeters and the corresponding geophysical corrections (e.g. SSB, wet tropospheric corrections) at each locations, rather than by an 
inconsistency between both vertical geodetic datum, especially since the signed is reversed in the Case of CryoSat-2. On the other hand, it is also interesting to note that the standard error is always higher for Ajaccio than for Senetosa, probably due to more complex land contaminations in the Ajaccio area as described in Bonnefond et al. (2013).

Table 6. SAR SSH biases for CryoSat-2 and Sentinel-3 (A\&B) at Ajaccio and Senetosa and their differences for passes overflying both sites.

\begin{tabular}{|l|c|c|c|}
\hline & Cryosat-2 (pass \#4794) & Sentinel-3A (pass \#741) & Sentinel-3B (pass \#741) \\
\hline SSH bias at Senetosa $(\mathrm{mm})$ & $+9 \pm 11$ & $+20 \pm 5$ & $-7 \pm 8$ \\
\hline SSH bias at Ajaccio $(\mathrm{mm})$ & $+20 \pm 13$ & $-2 \pm 7$ & $-22 \pm 14$ \\
\hline SSH bias difference $(\mathrm{mm})$ & -11 & +22 & +15 \\
\hline
\end{tabular}

In summary, for Sentinel-3A, the averaged SSH bias for both locations is $+9 \pm 5 \mathrm{~mm}$ in SAR mode and $+12 \pm 6 \mathrm{~mm}$ for PLRM mode. For Sentinel-3B, the averaged SSH bias (based only on 4 cycles) for both locations is $-14 \pm 5 \mathrm{~mm}$ in SAR mode and $+15 \pm 14 \mathrm{~mm}$ for PLRM mode. On cycle 9, Sentinel-3B was in LRM mode so this SSH bias of $+20 \mathrm{~mm}$ (green star on Figure 13) has been excluded from the statistics. However, this value is within the error bar of the PLRM time series, and so is not statistically different considering the small number of cycles.

Recent studies using the transponder installed in Crete show that the SAR range bias (inverse sign for SSH bias) for Sentinel-3A is $+6 \mathrm{~mm}$ (standard deviation of $12 \mathrm{~mm}$ ) (Mertikas et al., 2018) and $+8 \mathrm{~mm}$ (standard deviation of $12 \mathrm{~mm}$ ) (Garcia-Mondejar et al., 2017). For Sentinel-3B, preliminary result shows a range bias of $-3 \mathrm{~mm}$ (standard deviation of $18 \mathrm{~mm}$ ) (Garcia-Mondejar, personal communication). So our results are in very good agreement with transponder ones (differences within 15-17 mm) considering that difference between these two determinations can be due to the geophysical corrections (notably the SSB) as already mentioned for CryoSat-2 (section 4.4).

\section{Conclusions}

Table 7. SSH biases for all the studied missions

\begin{tabular}{|l|c|c|}
\hline Altimeters & SSH Bias $(\mathbf{m m})$ & Standard Error (mm) \\
\hline T/P ALT-A (MGDR++) & +24.5 & 8.3 \\
\hline T/P ALT-B (MGDR++) & +24.1 & 3.7 \\
\hline T/P POS-1 (MGDR++) & +11.9 & 9.7 \\
\hline Jason-1 (GDR-E) & +42.7 & 2.6 \\
\hline Jason-2 (GDR-D) & +16.2 & 2.3 \\
\hline Jason-3 (GDR-T) & -11.0 & 3.7 \\
\hline ERS-2 (REAPER) & +673.2 & 19.4 \\
\hline Envisat (FMRV3) & +491.4 & 5.7 \\
\hline CryoSat-2 (GPOD baseline C) & +6.6 & 4.3 \\
\hline SARAL/AltiKa (GDR-T) & -66.5 & 4.6 \\
\hline Sentinel-3A SAR (PDGS) & +9.2 & 5.2 \\
\hline Sentinel-3B SAR (PDGS) & -14.1 & 5.0 \\
\hline
\end{tabular}

Since the start of the Calibration/Validation activities in Corsica, 1998, the geodetic datum and instruments as well as the methodologies have been continuously upgraded in view of determining (in absolute sense) and monitoring the SSH bias of many altimetric space missions on the long term. This paper describes the different aspects (events, campaigns and 
regular controls) of the work that have been carried out in both the Senetosa and Ajaccio sites, and it presents the most recent results that have been achieved in terms of geodesy: leveling, GNSS positioning, in situ calibrations, and above all absolute SSH biases. A long process of "data archeology" has permitted to improve the consistency of the data series that enter in the overall monitoring and, more particularly, to understand the origin of the offsets that were identified before either at Ajaccio or Senetosa (see section 2 and Figure 5). We show that the long-term stability of any ground motion can be achieved at a precision better than few tenths of millimeters per year and that the regular leveling of in situ instruments (tide gauges) ensure a repeatability of the geodetic links to the reference markers of no more that $1 \mathrm{~mm}$ over several years. In addition, we highlighted the need for the careful long-term monitoring of in situ measurements measuring sea level; (i) performing pressure calibration for bottom pressure tide gauges or by using a contact probe for the radar ones, (ii) using multiple tide gauges to monitor their relative behavior and (iii) using independent measurement systems (e.g. GNSS-based) to compare SSH measurements. As a result, we show that from these processes it is possible to reach consistent measurements (in absolute sense) within less than $5 \mathrm{~mm}$ and with a stability better than $0.1 \mathrm{~mm} / \mathrm{yr}$ (Table 3 ).

In order to control the consistency between the Senetosa and Ajaccio geodetic sites, we have shown that we can achieve reliable SSH biases time series for altimetric missions (Sentinel-3A\&B, CryoSat-2 and SARAL/AltiKa) which overfly the two sites distant of $\sim 40 \mathrm{~km}$. But differences remain in the range of few millimeters to 2 centimeters (Table 6). The origin of that has been analyzed, however, and it can be multiple: (i) errors in the geodetic datum and in situ instruments, (ii) errors in the altimetric measurements itself (e.g. land contamination) and (iii) errors in the corrections of the altimetric measurements (e.g. Sea State Bias, wet tropospheric and ionospheric path delays). In case of SARAL/AltiKa (section 4.3), we showed that the direct (GNSS-based system) or indirect (coastal tide gauge) approaches which can be combined to measure the sea level give consistent SSH biases at the millimeter level.

Based on several updates of the geodetic datum established on both Corsica sites and using the 20-yr series of sea level measurements, we have computed a new series of absolute SSH biases for a number of altimetric missions, using the most recent reprocessing of their data. The results are synthetized in Table 7 and show that the absolute SSH biases are at the level of few millimeters to few centimeters for most of the missions except for ERS-2 and Envisat suggesting that a constant error (e.g. internal path delay) still remains, despite the recent reprocessing. For the longest time series the standard error is at the level of few millimetres giving a high level of confidence in our results. Moreover, independent approach based on transponders can help to discriminate sea side effects from range bias; in that case, the comparisons made for either CryoSat-2 (section 4.4) or Sentinel-3A\&B (section 4.5) show consistent results with the SSH biases determined in this study.

Acknowledgments: This study has been conducted and financed thanks to Centre National d'Etudes Spatiales (CNES), Centre National de la Recherche Scientifique (CNRS), and French Ministry of Research. Special thanks to Claude Gaillemin who takes care of all the instruments at Cape Senetosa since 1998 and performs the deployments of the GNSS-based system for sea level measurements. 


\section{REFERENCES}

Ablain, M., Philipps, S., Picot, N., Bronner, E., 2010. Jason-2 Global Statistical Assessment and Cross-

Calibration with Jason-1, Marine Geodesy, 33: 1, 162 - 185,

http://dx.doi.org/10.1080/01490419.2010.487805.

Ablain, M., Cazenave, A., Larnicol, G., Balmaseda, M., Cipollini, P., Faugère, Y., Fernandes, M. J., Henry, O., Johannessen, J. A., Knudsen, P., Andersen, O., Legeais, J., Meyssignac, B., Picot, N., Roca, M., Rudenko, S., Scharffenberg, M. G., Stammer, D., Timms, G., Benveniste, 2015. J. Improved sea level record over the satellite altimetry era (1993-2010) from the Climate Change Initiative project, Ocean Sci., 11, 67-82, http://dx.doi.org/10.5194/os-11-67-2015.

Altamimi, Z., Rebischung, P., Métivier, L., Collilieux, X., 2016. ITRF2014: A new release of the International Terrestrial Reference Frame modeling nonlinear station motions, Journal of Geophysical Research: Solid Earth, vol. 121, n. B8, pp. 6109-6131, http://dx.doi.org/10.1002/2016JB013098.

Bonnefond, P., P. Exertier, O. Laurain, Y. Menard, A. Orsoni, E. Jeansou, B. Haines, D. Kubitschek, Born, G., 2003a. Leveling Sea Surface using a GPS catamaran, Special Issue on Jason-1 Calibration/Validation, Part 1, Mar. Geod., Vol. 26, No. 3-4, 319-334.

Bonnefond, P., P. Exertier, O. Laurain, Y. Menard, A. Orsoni, G. Jan, Jeansou, E., 2003b. Absolute Calibration of Jason-1 and TOPEX/Poseidon Altimeters in Corsica, Special Issue on Jason-1 Calibration/Validation, Part 1, Mar. Geod., Vol. 26, No. 3-4, 261-284.

Bonnefond, P., Exertier, P., Laurain, O., Jan, G., 2010. Absolute Calibration of Jason-1 and Jason-2 Altimeters in Corsica during the Formation Flight Phase. Mar. Geod. Special Issue on Jason-2 Calibration/Validation, Part 1, 33(S1), 80-90, http://dx.doi.org/10.1080/01490419.2010.487790.

Bonnefond, P., B. Haines, Watson, C., 2011. In Situ Calibration and Validation: A Link from Coastal to Openocean altimetry, chapter 11 in Coastal Altimetry, pp 259-296, edited by S. Vignudelli, A. Kostianoy, P. Cipollini, J. Benveniste, Springer, ISBN: 978-3-642-12795-3.

Bonnefond, P., P. Exertier, O. Laurain, P. Thibaut, Mercier, F., 2013. GPS-based sea level measurements to help the characterization of land contamination in coastal areas, Advances in Space Research, Volume 51, Issue 8, Pages 1383-1399, ISSN 0273-1177, http://dx.doi.org/10.1016/j.asr.2012.07.007.

Bonnefond, P. Laurain, O. Exertier, P. Guillot, A. Picot, N., Cancet, M., Lyard, F., 2015. SARAL/AltiKa absolute calibration from the multi-mission Corsica facilities. Mar. Geod., SARAL/AltiKa special issue, 38(S1), 171-192, http://dx.doi.org/10.1080/01490419.2015.1029656.

Bonnefond, P., Laurain, O., Exertier, P., Boy, F., Guinle, T., Picot, N., Labroue, S., Raynal, M., Donlon, C., Féménias, P., Parrinello, T., Dinardo, S., 2018a. Calibrating SAR SSH of Sentinel-3A and CryoSat-2 over the Corsica facilities. Remote Sens., 10, 92, http://dx.doi.org/rs10010092.

Bonnefond, P., Verron, J., Aublanc, J., Babu, K.N., Bergé-Nguyen, M, Cancet, M., Chaudhary, A., Crétaux, J.F., Frappart, F., Haines, B.J., Laurain, O., Ollivier, A., Poisson, J.-C., Prandi, P., Sharma, R., Thibaut, P., Watson, C., 2018b. The benefits of the Ka-band as evidenced from the SARAL/AltiKa altimetric mission: Quality assessment and specificities of AltiKa data. Remote Sens., 10, 83, http://dx.doi.org/10.3390/rs10010083.

Brockley, D. J., Baker, S., Féménias, P., Martínez, B., Massmann, F.-H., Otten, M., Paul, F., Picard, B., Prandi, P., Roca, M., Rudenko, S., Scharroo, R., and Visser, P., 2017. REAPER: Reprocessing 12 Years of ERS-1 and 
ERS-2 Altimeters and Microwave Radiometer Data, in IEEE Transactions on Geoscience and Remote Sensing, vol. 55, no. 10, pp. 5506-5514, http://dx.doi.org/10.1109/TGRS.2017.2709343.

Brown, S., 2010. A novel near-land radiometer wet path-delay retrieval algorithm: application to the Jason2/OSTM advanced microwave radiometer geoscience and remote sensing. IEEE Trans. Geosci. Rems. Sens. 48 (4), 1986-1992, http://dx.doi.org/10.1109/TGRS.2009.2037220.

Cancet, M., Bijac, S. , Chimot, J., Bonnefond, P., Jeansou, E., Laurain, O., Lyard, F., Bronner, E., Féménias P., 2013. Regional in situ validation of satellite altimeters: calibration and cross-calibration results at the Corsican sites. Advances in Space Research, Volume 51, Issue 8, Pages 1400-1417, ISSN 0273-1177, http://dx.doi.org/10.1016/j.asr.2012.06.017.

Fu, L.-L. and Haines, B.J., 2013. The challenges in long-term altimetry calibration for addressing the problem of global sea level change, Advances in Space Research, Volume 51, Issue 8, Pages 1284-1300,ISSN 0273-1177, http://dx.doi.org/10.1016/j.asr.2012.06.005.

Garcia-Mondejar, A., Mertikas, S., Galanakis, D., Labroue, S., Bruniquel, J., Quartly, G., Féménias, P., Mavrocordatos, C., Wood, J., Garcia, G., et al., 2017. Sentinel-3 Transponder Calibration Results. In Proceedings of the Ocean Surface Topography Science Team Meeting, Miami, FL, USA, 23-27 October 2017; Available online:

https://meetings.aviso.altimetry.fr/fileadmin/user_upload/tx_ausyclsseminar/files/S3_OSTST_Poster_2017101 2_V8.pdf (accessed on 3 May 2019).

Garcia-Mondejar, A., Fornari, M., Bouffard, J., Féménias, P., Roca, M., 2018. CryoSat-2 range, datation and interferometer calibration with Svalbard transponder. Adv. Space Res., Pages 1589-1609, http://dx.doi.org/10.1016/j.asr.2018.01.008.

Haines, B. J., Dong, D., Born, G. H., Gill, S. K., 2003 The Harvest experiment: Monitoring Jason-1 and TOPEX/POSEIDON from a California offshore platform. In: Special Issue on Jason-1 Calibration/Validation, Part 1. Mar Geod 26(No 3-4):239-259.

Haines, B. J., Desai, S. D. and Born, G. H., 2010. The Harvest Experiment: Calibration of the Climate Data Record from TOPEX/Poseidon, Jason-1 and the Ocean Surface Topography Mission, Marine Geodesy, 33: 1, 91 - 113, http://dx.doi.org/10.1080/01490419.2010.491028.

Imel, D., 1994 Evaluation of the TOPEX dual-frequency Ionosphere correction, J. Geophys. Res., 99 (c12), pp 24895-24906, https://dx.doi.org/10.1029/94JC01869.

Mertikas, S.P., Donlon, C., Féménias, P., Mavrocordatos, C., Galanakis, D., Tripolitsiotis, A., Frantzis, X., Tziavos, I.N., Vergos, G., Guinle, T., 2018 Fifteen Years of Cal/Val Service to Reference Altimetry Missions: Calibration of Satellite Altimetry at the Permanent Facilities in Gavdos and Crete, Greece. Remote Sens., 10, 1557, http://dx.doi.org/10.3390/rs10101557.

Nocquet, J.-M., Sue, C., Walpersdorf, A., Tran, T., Lenôtre, N., Vernant, P., Cushing, M., Jouanne, F., Masson, F., Baize, S., Chéry, J., van der Beek, P. A., 2016. Present-day uplift of the western Alps. Sci. Rep. 6, 28404, http://dx.doi.org/10.1038/srep28404.

Watson C.S., White N., Coleman R., Church J., Morgan P., Govind R., 2004. TOPEX/Poseidon and Jason-1 Absolute Calibration in Bass Strait, Australia. In: Special Issue on Jason-1 Calibration/Validation, Part 2. Marine Geodesy, 27:1-2, 107-131Mar Geod 27(No 1-2):107-131, http://dx.doi.org/10.1080/01490410490465373. 
Watson C.S., White, N., Church, J., Burgette, R., Tregoning, P., Coleman R., 2011. Absolute Calibration in Bass Strait, Australia: TOPEX/Poseidon, Jason-1 and OSTM/Jason-2, Marine Geodesy _34:3-4, 242-260 , http://dx.doi.org/10.1080/01490419.2011.584834.

Woodworth, P., Moore, P., Dong, X., Bingley, R., 2004. Absolute Calibration of the Jason 1 Altimeter Using UK Tide Gauges. In: Special Issue on Jason 1 Calibration/Validation, Part 2. Marine Geodesy, 27:1-2, 95106Mar Geod 27(No 1 2):107 13195 106, http://dx.doi.org/10.1080/01490410490465328. 